\title{
Analysis of diet composition and morphological characters of the Peruvian lizard Microlophus stolzmanni (Squamata: Tropiduridae)
}

\author{
Antonia Beuttner ${ }^{1}$ and Claudia Koch ${ }^{2}$ \\ ${ }^{1}$ Institut für Mikrobiologie, Allmandring 31, 70569 Stuttgart, Germany. E-mail: antonia@ beuttner.de. \\ ${ }^{2}$ Zoologisches Forschungsmuseum Alexander Koenig (ZFMK), Adenauerallee 160, 53113 Bonn, Germany. \\ E-mail: c.koch@leibniz-zfmk.de.
}

\begin{abstract}
Analysis of diet composition and morphological characters of the Peruvian lizard Microlophus stolzmanni (Squamata: Tropiduridae). Microlophus stolzmanni is a diurnal lizard that is endemic to the dry forest of northern Peru. Little is known about the ecology of the species and the composition of its diet never has been studied. The stomach contents and morphological features related to feeding behavior are analyzed herein. Microlophus stolzmanni is a semi-herbivorous food generalist that also consumes animal items. All age groups prefer sedentary prey for which M. stolzmanni forages actively. As the lizard matures, plant material becomes a more important part of the diet.
\end{abstract}

Keywords: bite force, dry forest, feeding behavior, food niche, foraging strategy, Marañón River, ontogenetic change, stomach contents.

\begin{abstract}
Resumo
Análise da composição da dieta e características morfológicas do lagarto peruano Microlophus stolzmanni (Squamata: Tropiduridae). Microlophus stolzmanni é um lagarto diurno endêmico da floresta seca do norte do Peru. Pouco se sabe sobre a ecologia da espécie, e a composição de sua dieta nunca havia sido estudada. Analisamos aqui o conteúdo estomacal e características morfológicas relacionadas ao comportamento de alimentação. Microlophus stolzmanni é um lagarto generalista semi-herbívoro que também consome animais. Todos os grupos etários preferem presas sedentárias, que capturam por meio de forrageio ativo. À medida que os lagartos atingem a maturidade, o material vegetal torna-se uma parte mais importante da dieta.
\end{abstract}

Palavras-chave: comportamento alimentar, conteúdo estomacal, estratégia de forrageio, floresta seca, força da mordida, mudança ontogenética, nicho alimentar, rio Marañón.

Received 13 September 2018

Accepted 18 March 2019

Distributed June 2019 


\section{Introduction}

The genus Microlophus Duméril and Bibron, 1837 is a well-supported monophyletic group of 23 South American lizards characterized by apical disks on the hemipenes (Frost 1992, Harvey and Gutberlet 2000, Frost et al. 2001). These so-called "lava lizards" have a disjunct geographic distribution, unusual among terrestrial vertebrates (Benavides et al. 2007, 2009). Based on osteological characters, body scales, and skin folds, Microlophus is composed of two species groups: M. occipitalis and M. peruvianus groups (Dixon and Wright 1975, Frost 1992). The $M$. peruvianus Group contains two subgroups differing in their habitat preferences and feeding ecology. One group consists of three species that feed on crustaceans and algae in intertidal regions in Peru and Chile-Microlophus atacamensis (Donoso-Barros, 1960); M. heterolepis (Wiegmann, 1834); and M. quadrivittatus (Tschudi, 1845). The second group comprises seven species that feed on insects and terrestrial plants in dry terrestrial regions (i.e., valleys and deserts) in Ecuador, Peru, and Chile-M. peruvianus (Lesson, 1830); M. tarapacensis (DonosoBarros, 1966); M. theresiae (Steindachner, 1901); M. theresioides (Donoso-Barros, 1966); M. thoracicus (Tschudi, 1845); M. tigris (Tschudi, 1845); and M. yanezi (Ortiz-Zapata, 1980) (Ortiz and Serey 1979, Ibáñez et al. 2015). The M. occipitalis Group contains two subgroups differing in distribution patterns. Ten species are endemic to the Galápagos Islands- $M$. albemarlensis (Baur, 1890); M. barringtonensis (Baur, 1892); M. bivittatus (Peters, 1871); M. delanonis (Baur, 1890); M. duncanensis (Baur, 1890); M. grayii (Bell, 1843); M. habelii (Steindachner, 1876); M. indefatigabilis (Baur, 1890); M. jacobii (Baur, 1892); and M. pacificus (Steindachner, 1876). The remaining three species occur in continental regions of Ecuador and Peru-M. koepckeorum (Mertens, 1956); $M$. occipitalis (Peters, 1871); and M. stolzmanni (Steindachner, 1891) (Dixon \& Wright 1975, Frost 1992, Benavides 2007, 2009).
In an herpetological inventory of different inter-Andean dry-forest regions in northern Peru, Microlophus stolzmanni was abundant at most of the study sites (Koch et al. 2018). This species is endemic to northern Peru and occurs in the departments of Amazonas, Ancash, Cajamarca, La Libertad, Lambayeque, and Piura at elevations of 394-1952 m a.s.l. (Dixon and Wright 1975, Venegas et al. 2016, Koch et al. 2018). This diurnal, scansorial lizard is mostly commonly is found on the ground, but it also occurs on stones or rocks, tree trunks, or on branches of shrubs and cacti plants (Dixon and Wright 1975, Venegas et al. 2016). Adult males and females are sexually dimorphic in coloration and size. In females, the eyes and nostrils are framed in red and the ventral and lateral surfaces of the head are pigmented with gray, white, yellow, or orange. The throat is gray to brown, and the dorsum olive green with white dots. Females are distinctly smaller than males and have low dorsal crest (Figure 1). In contrast, the ventral part of the head of males is gray or cream-colored with oblique thin dark brown lines. The throat is pigmented with black and sometimes, some yellow. Dorsolaterally, the body bears two thin, parallel black lines. The males are bigger and more massive than the females, and have a pronounced dorsal crest (Figure 2).

The diet of a congener, Microlophus thoracicus, consists of a great deal of plant material, as well as invertebrates, such as ants and insect larvae; this suggests that $M$. thoracicus is semi-herbivorous in contrast to the insectivorous species $M$. peruvianus and $M$. occipitalis. The head of M. thoracicus is higher and broader than those of the insectivorous congeners, thereby suggesting that $M$. thoracicus has a stronger bite force than do the insectivores (Pérez et al. 2015). Based on his observation that M. stolzmanni and M. thoracicus have similar cranial dimensions, Toyama (2016) predicted the species would have similar semi-herbivorous diets; however, the diet of $M$. stolzmanni has yet to be documented.

The following analysis of the diet in populations of Microlophus stolzmanni from the 


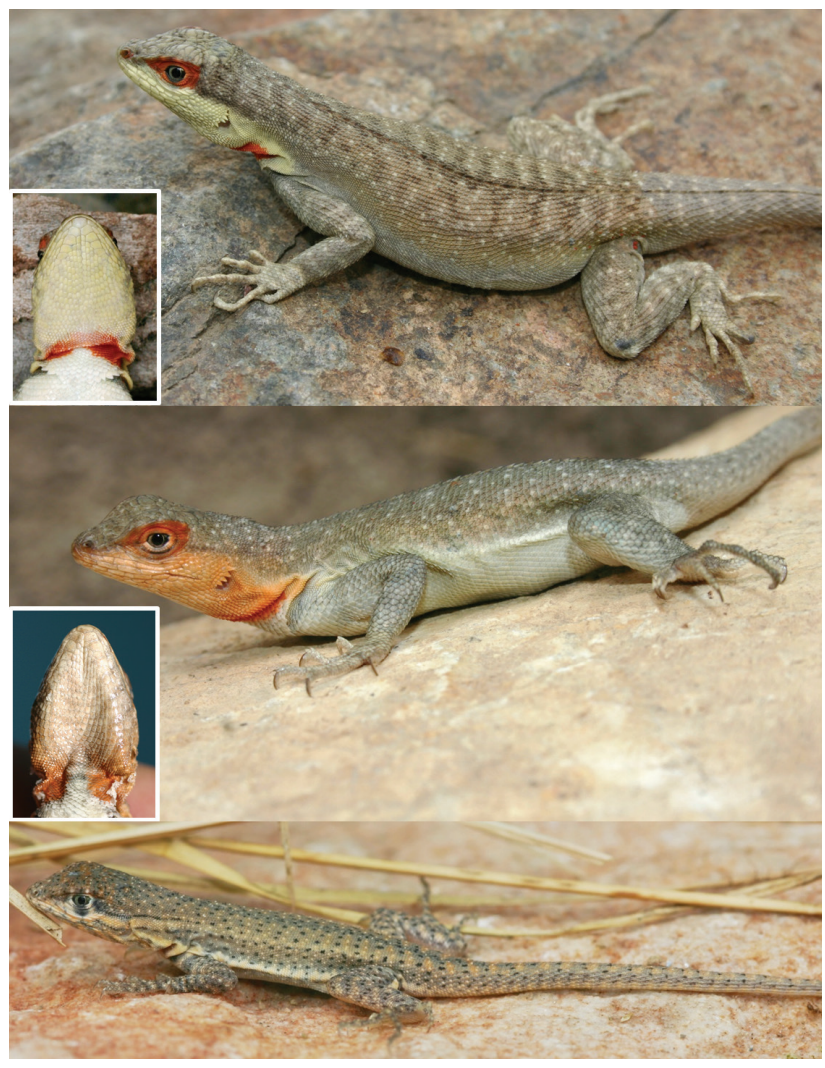

Figure 1. Two different color patterns of female Microlophus stolzmanni with close-ups of the ventral part of the heads (top and middle) and coloration of a juvenile specimen (bottom) from Peru.

inter-Andean dry-forest valleys in northern Peru was conducted to examine whether there are sexual differences and ontogenetic changes in the diet of this species. In addition, we describe the foraging strategy of the species, and determine whether $M$. stolzmanni is a food generalist or specialist. Morphological analyses were performed to explain differences in feeding behavior between age and sex groups.

\section{Materials and Methods}

Fieldwork

As part of an intensive herpetological inventory in the inter-Andean dry-forest valleys of the Marañón River and its tributaries, a total

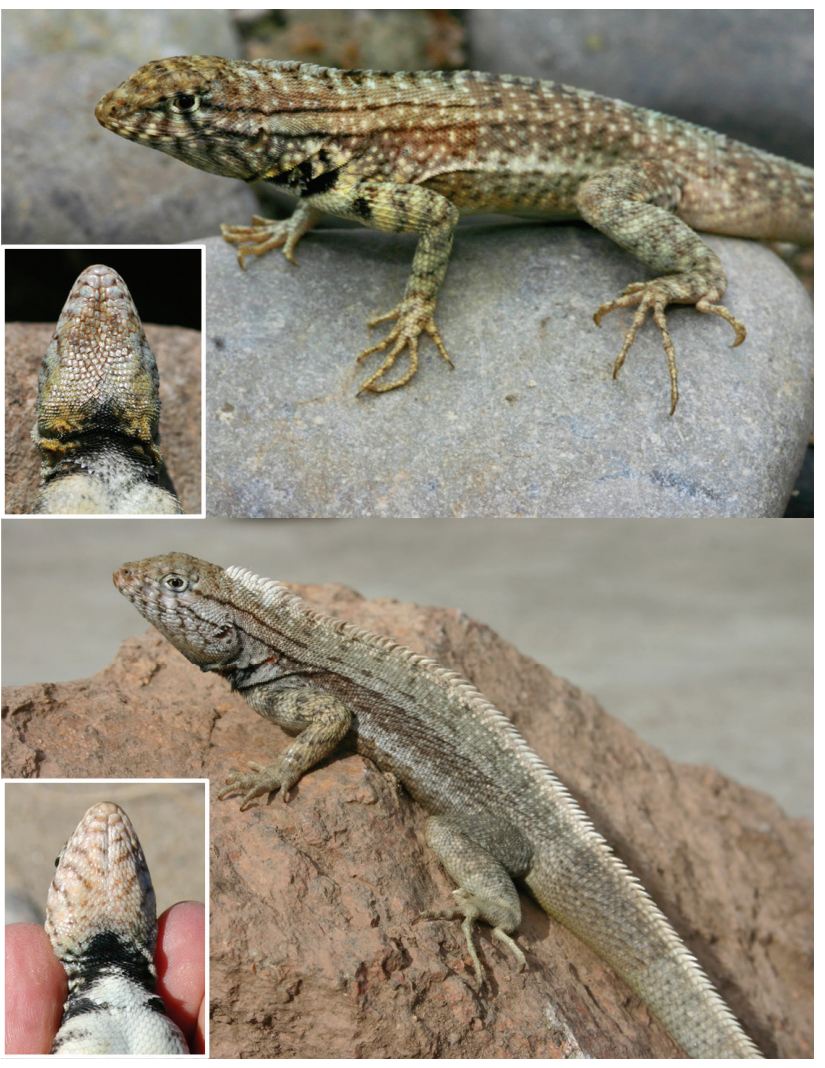

Figure 2. Two different color patterns of male Microlophus stolzmanni with close-ups of the ventral part of the heads from Peru.

of 142 individuals of Microlophus stolzmanni was collected (Koch et al. 2018). Most of these lizards were deposited in the collections of the Centro de Ornitología y Biodiversidad (CORBIDI) in Lima, Peru, and the Museo de Historia Natural de la Universidad Nacional de San Agustín (MUSA) in Arequipa, Peru. However, CK was allowed to export 49 individuals (24 males, 14 females, 11 juveniles) for further examination and to add them to the collection of the Zoologisches Forschungsmuseum Alexander Koenig (ZFMK) in Bonn, Germany. These specimens were used for the dietary analysis. The lizards were collected in the course of different field surveys between July 2005 and October 2010 from various localities, and were encountered during visual surveys. During the 
day, individuals were found either basking in the sun on stones, stone walls, rocks, or logs until 17:30 hr or actively running around and searching for food on tracks or in low grass vegetation. Some lizards were found active until 23:00 hr. Nevertheless, after nightfall ( 19:00 hr), most individuals were found sleeping or resting hidden under stones or logs, in holes of stone walls, or unhidden on trunks, shrubs, cacti plants, or on roofs (Koch et al. 2018). Of the lizards included in this analysis, most were collected during their active hours. Only four individuals (ZFMK 88722, 91778-91779, 91783) were collected while they were asleep; because these lizards were found within $3 \mathrm{hr}$ after nightfall, they probably had not been asleep for a long. The other lizards collected by $\mathrm{CK}$ are, as follow: three in July 2005 (ZFMK 85021-85023); three in May 2008 (ZFMK 88715-88717); eight in July 2008 (ZFMK 88718-88725); eight in March 2009 (ZFMK 90839-90846); eight in April 2009 (ZFMK 90847-90854); three in December 2009 (ZFMK 90855-90857); 10 in January 2010 (ZFMK 91771-91780); and six in October 2010 (ZFMK 91781-91786). Collecting localities are given in Appendix I. The lizards were captured by hand, with a fishing net or a fishing rod with a loop of cord, or with a sling shot. The animals were euthanized by an injection of the veterinary anesthetic T61 the following morning, no more than $10 \mathrm{hr}$ after their capture, to assure that the stomach contents were in the best possible condition for identification. After fixation in $10 \%$ formalin for $24-48 \mathrm{hr}$, the lizards were preserved in $70 \%$ ethanol.

\section{Data Analysis}

The sex of the lizards was determined by coloration, the internal reproductive organs (testicles or ovaries), or by the presence of everted hemipenes. Lizards lacking mature gonads and lacking the typical coloration of adults described above were considered to be juveniles.
Dial calipers $(0-150 \mathrm{~mm}$; to the nearest 0.01 $\mathrm{mm}$ ) were used to measure snout-vent length (SVL), head length, head width, head height, body width, and tail length of each lizard, as well as to determine the length and width of prey items. Measurements of head length, head width, and head height are the same as those of Meyers et al. (2002). Stomachs and fat bodies were removed from the preserved specimens; the stomachs were dissected to remove the contents and examine them in a Petri dish under a stereomicroscope following the methodology of Bährmann (2011). Weights of lizards, stomachs, and fat bodies were determined with a digital weighing machine (Almasa ${ }^{\circledR}$ MT 7; max. 200 g; to the nearest $0.01 \mathrm{~g}$ ). The food items were assigned to 14 prey categories; of these 13 were identified to order or family level and the $14^{\text {th }}$ category was reserved for all undetermined taxa, including unidentifiable parts of athropods and plant material, which was not identified taxonomically, but noted as leaves, fibers, seeds and fruits. Contents of the stomach were categorized as either "sedentary" or "mobile" prey to define the foraging strategy of the lizards. In addition, the contents were identified as "soft," "medium-hard," or "hard" prey to analyze the bite force used by the lizard (explained in Beuttner and Koch 2019).

The following variables were measured: the number of consumed items $(N)$; the percent by number $\left(N_{\%}\right)$; the frequency of occurrence $(F$, number of stomachs in which a given prey category was found); the percent by frequency $\left(F_{\%}\right)$; the volume $\left(\mathrm{V} \mathrm{mm}^{3}\right)$; and the percent by volume $\left(\mathrm{V}_{\%}\right)$ for each prey category. The length and width of the individual prey item was used to calculate its volume (V) with the formula for an ellipsoid of Colli and Zamboni (1999). The data were pooled for all specimens and were subsequently separated by sex/age classes.

Every head dimension was regressed against SVL to compare head dimensions among lizard groups. A residual analysis was performed on 
these data to avoid the influence of different SVL values. Likewise, the weights of stomachs and fat bodies were regressed against body weight and a residual analysis conducted to avoid the influence of body weights. Before comparisons were made, we tested the normality of residuals with the Shapiro-Wilk-Test. Depending on the result, parametric (T-Test) or non-parametric (Mann-Whitney U-Test) tests were used to determine statistical differences between groups. All statistical tests were executed in OriginPro version 8.0724 (OriginLab, Northampton, MA, USA).

We used the dimensions of complete prey items as a reference to estimate the dimensions and calculate the volumes of fragmented prey items. Complete prey items of each prey category were categorized according to the mean values of their sizes (i.e., exceedingly large, large, medium-sized, small, minute; Appendix II). We calculated the niche breadth by using the (1) Simpson-Index B (Simpson 1949) to quantify the diversity of prey used by the animals, and (2) the inverse of the Simpson-Index B' to compare the values with other published data. Values for $B$ vary from 0 (no diversity, exclusive use of a single prey type, specialist) to 1 (highest diversity, prey items of all categories, generalist), whereas values for B' vary from 1 (no diversity, exclusive use of a single prey type, specialist) to $\mathrm{n}$ (highest diversity, prey items of all categories, generalist). In addition, the Index of Relative Importance (IRI) of each prey category in relation to the total food spectrum was calculated (Pinkas 1971, Pinkas et al. 1971). Last, niche overlap $\left(\mathrm{O}_{\mathrm{j} \mathrm{k}}\right)$ in the food spectrum between the different groups (females, males, juveniles, adults) was estimated by the Pianka-Index (Pianka 1974). The values for $\mathrm{O}_{\mathrm{jk}}$ vary from 0 (no overlap, groups compared have a completely different food spectra) to 1 (complete overlap, groups compared have the same food spectrum). All formulas used to calculate V, B, B', IRI, and $\mathrm{O}_{\mathrm{jk}}$ are shown and explained in Beuttner and Koch (2019).

\section{Results}

\section{Morphological Analysis}

Female Microlophus stolzmanni are significantly smaller and lighter than males (Length: U-Test, $\mathrm{U}=16, \mathrm{Z}=-4,5846, p=p<$ 0.001; Appendix III). The head dimensions of all individuals are positively correlated with SVL (head length against SVL: $y=0.2424 x+1.9509$, $\mathrm{R}^{2}=0.955$; head width against SVL: $\mathrm{y}=$ 0.1639x + 1.3293, $\mathrm{R}^{2}=0.967$; head height against SVL: $\mathrm{y}=0.1292 \mathrm{x}+0.7496, \mathrm{R}^{2}=$ 0.9451 ). Adults have significantly smaller head dimension residuals than do juveniles (T-Test; length: $\mathrm{t}=-3.64235$; width: $\mathrm{t}=-4.95493$; height: $\mathrm{t}=-1.89606$; all $p<0.05$ ), but there are no significant differences between males and females (T-Test; length: $\mathrm{t}=-1.11708, p=0.27$; width: $\mathrm{t}=-0.00822, p=0.99$; height: $\mathrm{t}=$ $-0.27056, p=0.79$; Appendix III).

We found fat bodies in 38 individuals (77.6\%) of Microlophus stolzmanni (22 males, 11 females, 5 juveniles). The residuals for the weights of stomachs and body fat do not differ among the groups (U-Test; fat body: $\mathrm{U}_{\text {female/male }}=$ $223, \mathrm{U}_{\text {female/juvenile }}=102.5, \mathrm{U}_{\text {male/juvenile }}=159, \mathrm{U}_{\text {adult } /}$ juvenile $=261.5$, all $p<0.05$; stomach weight: $\mathrm{U}_{\text {female }}$ male $=190, \mathrm{U}_{\text {female/juvenile }}=68, \mathrm{U}_{\text {male/juvenile }}=92, \mathrm{U}_{\text {adult } /}$ juvenile $=160$, all $p<0.05 ;$ Appendix III).

\section{Stomach Contents}

The composition of the stomach contents of the total sample of Microlophus stolzmanni, as well for specimens grouped by sex/age classes is summarized in Table 1. A total of 855 items, representing 802 prey items $\left(N_{\%}=93.8 \%\right)$ and 49 pieces of plant material $\left(N_{\%}=5.7 \%\right)$, and 4 stones $\left(N_{\%}=0.5 \%\right)$ were identified. The plant material was almost exclusively comprised of entire seeds and leaves. We found prey items in $44\left(F_{\%}=97.8 \%\right)$, plant material in $25\left(F_{\%}=\right.$ $51.0 \%)$, and stones in $4\left(F_{\%}=8.2 \%\right)$ stomachs. The percent by volume of the prey items $\left(\mathrm{V}_{\%}=\right.$ $59.5 \%$ ) is slightly higher than that of the plant 
material $\left(\mathrm{V}_{\%}=40.3 \%\right)$, whereas that of the inorganic material is negligible $\left(\mathrm{V}_{\%}=0.2 \%\right)$. With respect to the IRI, the prey items (IRI = 14992.7) played the major role in the diet of $M$. stolzmanni. The IRI of plant material is 2555.8 and that of inorganic material an almost negligible 6.22. In 33 adult stomachs, we found 550 food items with a total volume of $\mathrm{V}=$ $27490.7 \mathrm{~mm}^{3}$, whereas 11 juvenile stomachs had 305 food items with a total volume of $\mathrm{V}=778.4$ $\mathrm{mm}^{3}$.

In adults and juveniles, the prey items constituted the major part of the diet with an IRIs of 14911.0 and 19840.0, respectively. Plant material is less important in adults (IRI = 3539.4), and almost negligible in juveniles (IRI $=6.1$ ).

In 22 stomachs of male Microlophus stolzmanni, 347 food items with a total volume (V) $24026.6 \mathrm{~mm}^{3}$ was found, whereas and in the stomachs of 12 females, 203 food items with a total volume $3464.2 \mathrm{~mm}^{3}$ was found. Prey items are more important in both males and females, with IRIs of 13738.1 and 16873.0, respectively; in contrast, plant material accounts for IRIs of 4527.4 and 1758.1, respectively. Inorganic material is almost negligible in all groups, with IRIs of 6.6 in adults, 0.3 in juveniles, 6.6 in males, and 9.4 in females.

The most important prey category is Formicidae with respect to the number of consumed items $\left(N=462, N_{\%}=54.0 \%\right)$, the number of stomachs which contained the category $\left(F=31, F_{\%}=68.9 \%\right)$, and the IRI 4002.5 , whereas formicids rank fourth in the volume $\left(\mathrm{V}=1147.6 \mathrm{~mm}^{3} ; \mathrm{V}_{\%}=4.1 \%\right)$. The prey having the greatest volume is lepidopteran larvae $\left(\mathrm{V}=5076.9 \mathrm{~mm}^{3} ; \mathrm{V}_{\%}=18.0 \%\right)$; these rank second in frequency $\left(F=15, F_{\%}=33.3\right)$ and IRI (758.6) and third in number of consumed items $\left(N=41, N_{\%}=4.8 \%\right)$. Adult Lepidoptera rank second in volume $(\mathrm{V}=$ $3453.6 \mathrm{~mm}^{3} ; \mathrm{V}_{\%}=12.2 \%$ ), third in IRI (398.6), and fourth in number of consumed items $(N=$ $\left.35, N_{\%}=4.1 \%\right)$. Isopterans are second in number of consumed items $\left(N=157, N_{\%}=\right.$ $18.4 \%)$, whereas coleopterans rank third in frequency $\left(F=14, \quad F_{\%}=31.1 \%\right)$ and Heteroptera ranks third in volume $(\mathrm{V}=2922.8$ $\left.\mathrm{mm}^{3} ; \mathrm{V}_{\%}=10.3 \%\right)$.

On closer inspection of the IRI values, Formicidae is the most important prey category in the diet of all groups: adults, 3150.5; juveniles, 6721.7; males, 1317.4; and females, 7696.5 (Table 2). Lepidopteran larvae are the second most important category in adults with an IRI of 755.7; males, 720.2; and females, 390.9; however, they rank third in juveniles with an IRI of 618.1. In juveniles, adult Lepidoptera ranked second with an IRI of 952.6, whereas this prey ranks fourth in all other groups with the following IRI values: adults, 321.2; males, 321.6; and females, 191.5. Isoptera ranks third in adults $(I R I=397.0)$ and males (IRI $=678.9)$, and also is of some importance in the diet of juveniles (IRI = 274.3); Isoptera is least significant in females, which have an IRI of 23.3. The third most important prey category in females is Heteroptera (IRI $=344.2$ ), which ranked fifth in adults (IRI $=201.2$ ), as well as in males (IRI = 247.3), and is almost insignificant in the diet of juveniles (IRI $=17.5)$. The order Araneae is of some importance in the diet of juveniles (IRI = 460.4; Table 2).

With regard to the food niche breadth, the Simpson-Index for the species is $\mathrm{B}=0.64$ and the inverse Simpson-Index is $\mathrm{B}^{\prime}=2.79$. Males have the highest values $\left(\mathrm{B}=0.74, \mathrm{~B}^{\prime}=3.87\right)$ and females the lowest $\left(\mathrm{B}=0.27, \mathrm{~B}^{\prime}=1.37\right)$. Furthermore, there is a significant difference between adults $\left(\mathrm{B}=0.71, \mathrm{~B}^{\prime}=3.44\right)$ in contrast to juveniles $\left(\mathrm{B}=0.41, \mathrm{~B}^{\prime}=1.71\right.$; Table 3$)$.

The Pianka-Index $\left(\mathrm{O}_{\mathrm{jk}}\right)$ indicated that the highest niche overlap value is between females and juveniles $\left(\mathrm{O}_{\mathrm{jk}}=1.00\right)$, whereas males and females had the lowest overlap value $\left(\mathrm{O}_{\mathrm{jk}}=\right.$ 0.80). Adults and juveniles have the second highest overlap value $\left(\mathrm{O}_{\mathrm{jk}}=0.95\right)$ and males and juveniles rank third in food niche overlap $\left(\mathrm{O}_{\mathrm{jk}}=\right.$ $0.83)$. 


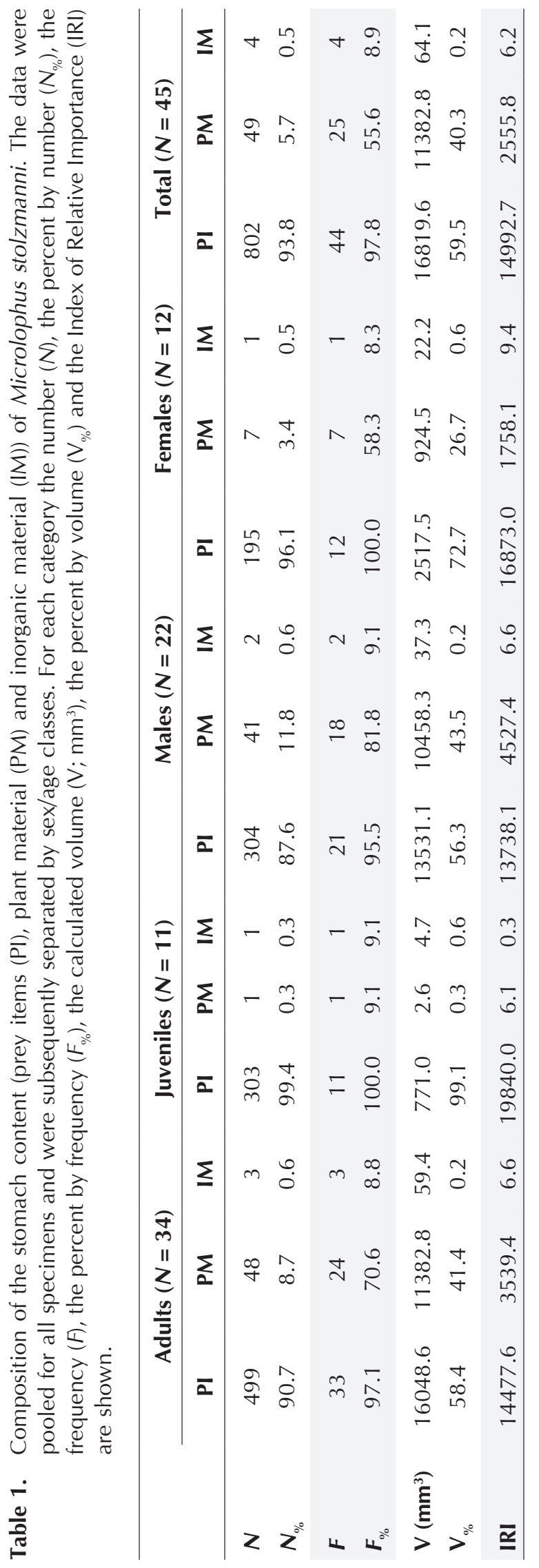

\section{Foraging Strategy}

The 41 stomachs of Microlophus stolzmanni contained 776 prey items with a total volume of $\mathrm{V}=15413.8 \mathrm{~mm}^{3}$. One hundred and ten prey items were assigned to the mobile prey category $\left(N_{\%}=14.2 \%\right)$ with a volume of $\mathrm{V}=7025.0 \mathrm{~mm}^{3}$ $\left(\mathrm{V}_{\%}=45.6 \%\right)$, whereas $666\left(N_{\%}=85.8 \%\right)$ were classified as sedentary prey with a volume of $\mathrm{V}$ $=8388.8 \mathrm{~mm}^{3}\left(\mathrm{~V}_{\%}=54.4 \%\right)$. We found mobile prey in 34 stomachs $\left(F_{\%}=82.3 \%\right)$ and sedentary prey in $38\left(F_{\%}=92.7 \%\right)$. The IRI of sedentary prey (12997.4) is 2.6 times higher than the IRI of mobile prey (4955.9). The different lizard groups (i.e., adults, juveniles, males, females) have considerably higher values for sedentary prey items than for mobile prey. Moreover, sedentary prey items appear the most frequently in the stomachs in all groups. The volume of consumed sedentary prey items is slightly higher in all groups than the volume of mobile prey, except for females which consume a slightly higher volume of mobile prey than sedentary prey. The IRI for sedentary prey is between 2.5 and 3 times higher than for mobile prey for all specimen groups (Table 4).

\section{Bite Force}

We identified 825 prey items and plant material in 45 stomachs of Microlophus stolzmanni. Of these, 67 were categorized as hard prey $\left(N_{\%}=8.1 \%\right)$ with a volume of $\mathrm{V}=$ $11860.8 \mathrm{~mm}^{3}\left(\mathrm{~V}_{\%}=44.3 \%\right), 644\left(N_{\%}=78.1 \%\right)$ as medium-hard prey with a volume of $\mathrm{V}=$ $6115.1 \mathrm{~mm}^{3}\left(\mathrm{~V}_{\%}=22.8 \%\right)$, and $114\left(N_{\%}=\right.$ $13.8 \%)$ as soft prey with a volume of $\mathrm{V}=8820.7$ $\left(\mathrm{V}_{\%}=32.92 \%\right)$. Hard prey items were present in 32 stomachs $\left(F_{\%}=71.1 \%\right)$, medium-hard prey in $33\left(F_{\%}=73.3 \%\right)$, and soft prey in 29 stomachs $\left(F_{\%}=64.4 \%\right)$. The IRI of medium-hard prey (3725.1) is the highest, followed by the IRI of hard prey (3725.1). All groups of lizards consumed greater numbers of medium-hard prey items than either hard or soft prey. 


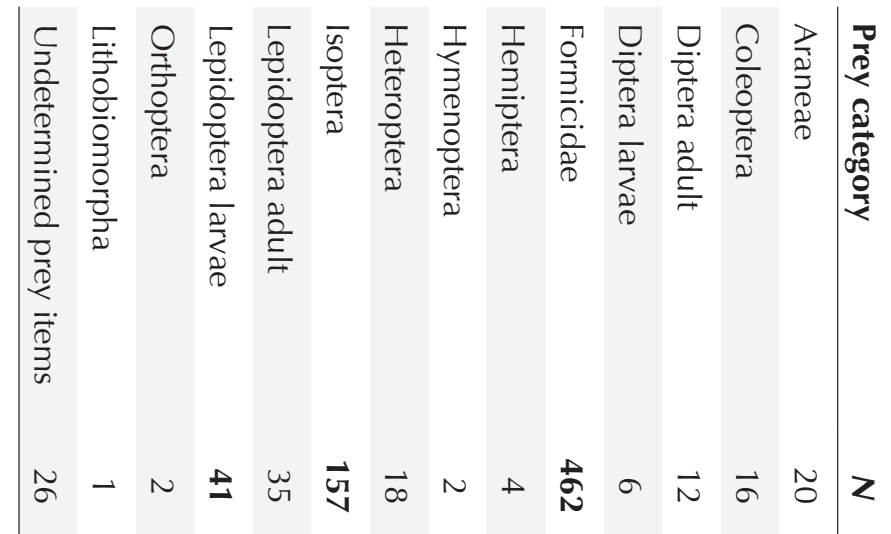

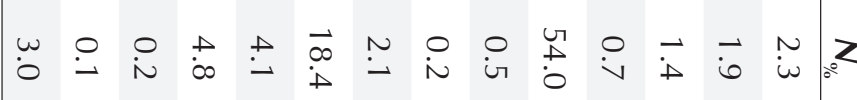

$$
\begin{aligned}
& \vec{D}-N \vec{v}=a \sigma N N \underline{\underline{\omega}}+N \vec{\Phi} \vec{\omega} T
\end{aligned}
$$

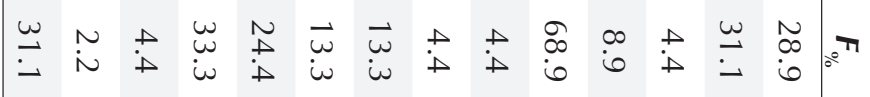

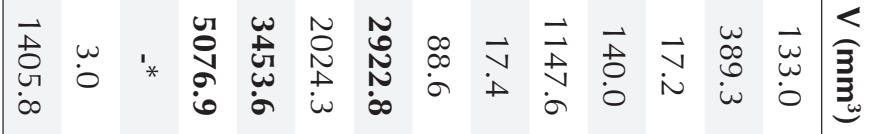

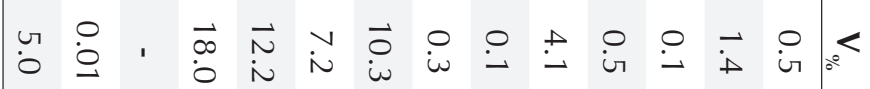

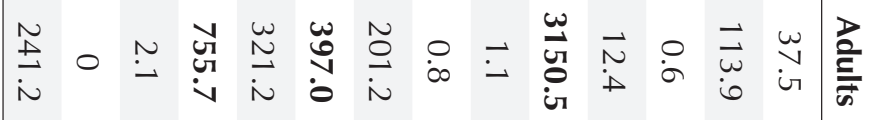

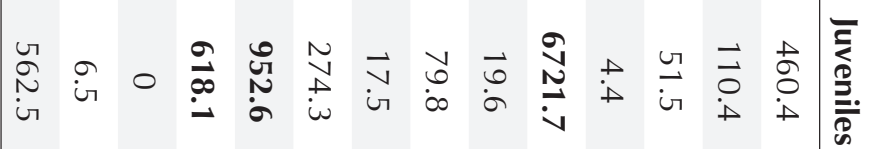

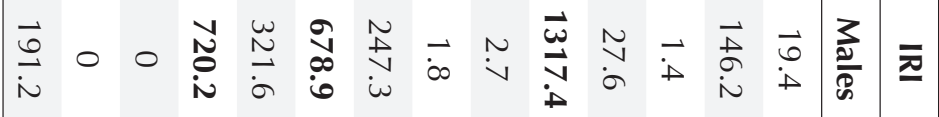

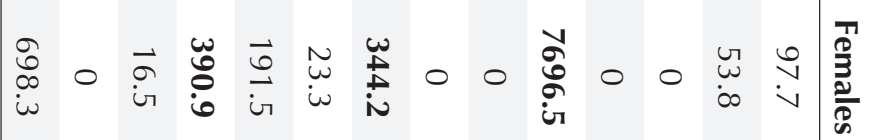

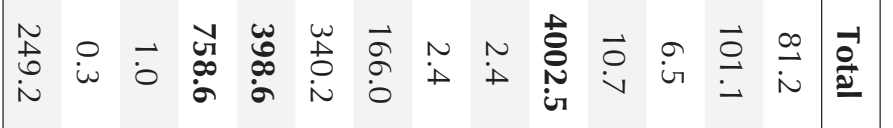


Table 3. Diversity in the dietary spectrum of Microlophus stolzmanni. The Simpson-Index (B), the inverse Simpson-Index (B'), and the number of consumed prey categories ( $\mathrm{S}$, including plant material) are given for adults, juveniles, males, and females separately and for all specimens together, respectively.

\begin{tabular}{lccccc}
\hline & Adults & Juveniles & Males & Females & Total \\
\hline B & 0.71 & 0.41 & 0.74 & 0.27 & 0.64 \\
B' $^{\prime}$ & 3.44 & 1.71 & 3.87 & 1.37 & 2.79 \\
S & 13 & 13 & 12 & 9 & 14 \\
\hline
\end{tabular}

There are no great differences in the numbers of hard or soft prey items consumed, except in juveniles, which consumed conspicuously more soft prey than hard prey items. In females, all prey items appeared in the stomachs with the same frequency. In males and in adults, hard prey items are encountered more frequently than soft prey items. In contrast, in juveniles the frequency of soft prey is the higher than that of hard prey items. In males and adults, hard prey items have a greater volume than does mediumhard prey. In females, the volume of mediumhard prey is higher than that of soft prey. In juveniles, the volume of soft prey is higher than that of hard prey. The IRI for medium-hard prey is higher in all groups than that of soft prey; however, in juveniles, the IRI is lowest in for hard prey (Table 5).

\section{Discussion}

This first detailed study of the diet of Microlophus stolzmanni is based on lizards collected in the dry forest of northern Peru. Our findings suggest that $M$. stolzmanni is a semiherbivorous food generalist that also consumes animal items. All age groups prefer sedentary prey and M. stolzmanni can be considered to actively forage. However, as the lizard matures, plant material becomes more prevalent in the diet.

Male Microlophus stolzmanni are significantly larger than females, as has been observed in

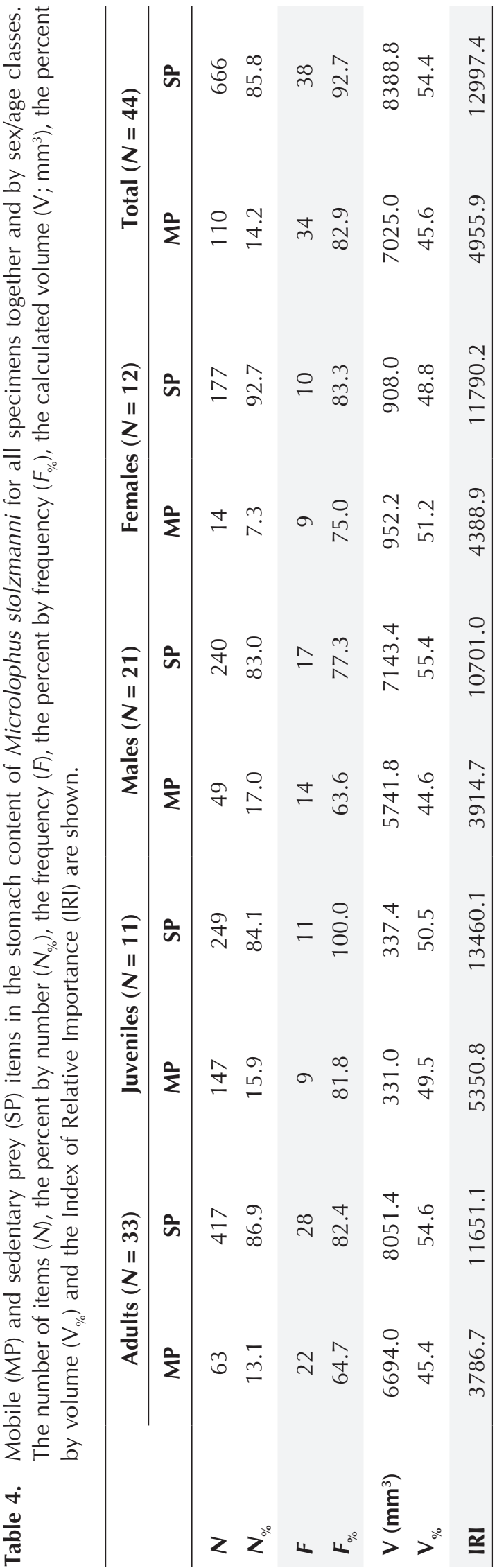




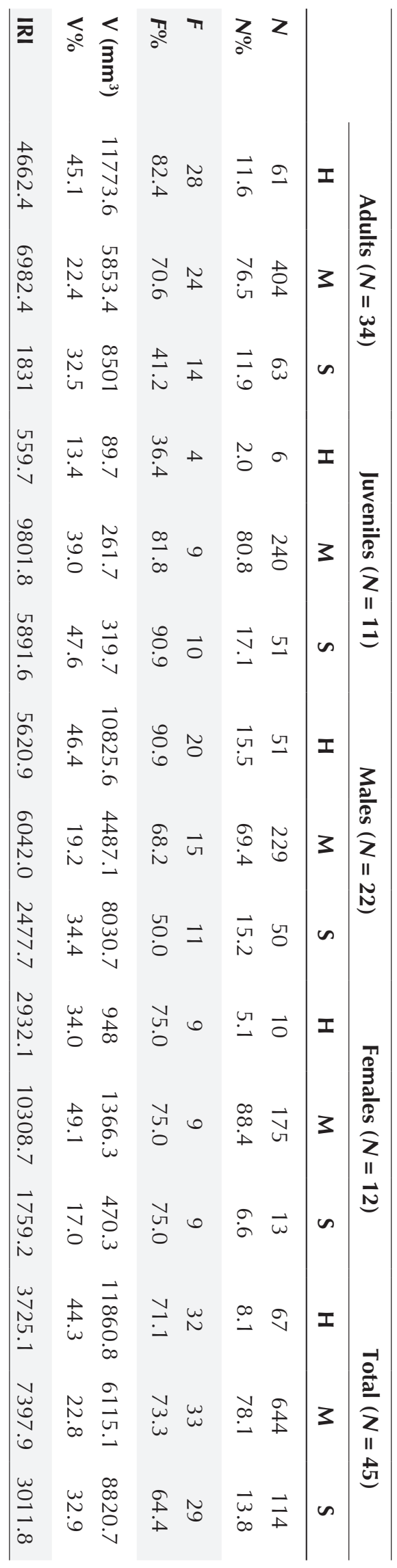

congeners, such as $M$. atacamensis and $M$. occipitalis (Watkins 1996, Vidal et al. 2002).

In the absence of significant differences in stomach weight and fat body weight in proportion to body weight among our defined groups of Microlophus stolzmanni, we assume that all members of our sample had a similar nutritional state. We observed a high percent by volume of both prey items $\left(\mathrm{V}_{\%}=59.5 \%\right)$ and plant material $\left(\mathrm{V}_{\%}=40.3 \%\right)$. This confirms Toyama's (2016) assumption of a semi-herbivorous dietary spectrum in $M$. stolzmanni, based on his investigations of the head dimensions of the species. However, animal items are more prevalent in the diet of adults (IRI $=14477.6$ ) than plant material (IRI $=3539.4)$, and plant material is relatively unimportant to juveniles $(I R I=6.1)$. Thus, juveniles are insectivorous and adults are semi-herbivorous. This ontogenetic diet shift occurs in many lizard species that consume insects as juveniles and become herbivorous or semi-herbivorous as adults (e.g., Estes and Williams 1984, Dessem 1985, Cooper and Vitt 2002, van Leeuwen et al. 2011). Troyer (1982) observed that juvenile lizards lack the intestinal cellulose-degrading microflora that enables adult lizards to digest plant material. Moreover, juvenile lizards require animal protein to promote growth and development (Mayhew 1963, Johnson and Lillywhite 1979). Toyama (2016) assumed that the congener of $M$. stolzmanni-M. thoracicusalso has a semi-herbivorous diet, because the heads of both species are significantly higher and wider than those of the insectivorous species, $M$. peruvianus and M. occipitalis.

Having found only an insignificant amount of inorganic material in the stomachs of Microlophus stolzmanni, we assume that its consumption was unintentional.

With a value of $\mathrm{B}=0.64$ for the SimpsonIndex, Microlophus stolzmanni can be considered as a food generalist characterized by consumption of a great diversity food items. However, given inverse Simpson-Index of $\mathrm{B}^{\prime}=2.79$, the diversity is lower than those of $M$. thoracicus $\left(\mathrm{B}^{\prime}=6.97\right)$ and M. tigris $\left(\mathrm{B}^{\prime}=4.33\right)$ (Pérez et al. 2015) and 
nearly the same as the dietary spectrum of $M$. peruvianus (B' = 2.97; Quispitúpac and Pérez 2009).

Male and female Microlophus stolzmanni have the greatest disparity in food diversity of all of the groups; the diet of males is more diverse $(\mathrm{B}=0.74)$ than that of females $(\mathrm{B}=0.27)$. Accordingly, only male M. stolzmanni are food generalists, whereas females have a more specialized diet. The diet of juveniles is more diverse $(B=0.41)$ than that of females, but much lower than that of males. Therefore, juveniles, like females are not food generalists. The niche overlap in the dietary spectra of the various groups of $M$. stolzmanni is comparatively high with all values for $\mathrm{O}_{\mathrm{jk}} \geq 0.8$. The "medium-hard prey" category is preferred by all groups of $M$. stolzmanni; however, as measured by percent by volume, "hard prey" is greater in adults, males, and in all specimens together. These observations may reflect our placement of plant material in the category of hard prey. Plant material was counted as one item when found in the same stomach, thereby accounting for the relatively low number of hard prey items. Male $M$. stolzmanni have a greater diversity of food items than do females and juveniles because the higher and wider heads of males enable them to produce a higher bite force (McBrayer and Corbin 2007, Miles et al. 2007, Toyama 2016) and thus consume larger and harder dietary items (Herrel et al. 2001a,b, Verwaijen et al. 2002, Herrel 2007, Huyghe et al. 2009). Females also have larger heads than juveniles, but the difference is far less pronounced than that between males and juveniles. Other factors also may influence dietary variation among the groups, such as seasonal variation in temperature or differing microhabitat usage (Paulissen 1988, Griffiths et al. 1996). Furthermore, hard food items do not decompose as rapidly as soft items. Some lizards were euthanized as many as $10 \mathrm{hr}$ after capture. The longer the time before euthanization, the higher the probability that soft items may have decomposed such that it might seem that there was a greater proportion of hard items. However, most lizards were euthanized more quickly.
All M. stolzmanni examined mainly contained clumped, colony-building (e.g., Formicidae and Isoptera) or sedentary prey (e.g., Lepidoptera larvae), with mobile prey being less frequent. Sedentary or clumped prey usually is consumed by active foragers (Pianka 1970, Pianka and Parker 1975, Huey and Pianka 1981, Nagy et al. 1984, Magnusson et al. 1985, Toft 1985, Anderson and Karasov 1988, Bergallo and Rocha 1994). Thus, M. stolzmanni should be considered to be an active forager, which is consistent with our field observations of several lizards actively foraging on the ground by day.

Recently we analyzed the diet of the arboreal lizard Polychrus peruvianus (Beuttner and Koch 2019) from primarily the same Peruvian localities from which we collected $M$. stolzmanni. Although both species have access to the same food resources, we found differences in the niche breadth values of both species. Polychrus peruvianus $\left(\mathrm{B}^{\prime}=5.65\right)$ has a much more diverse diet than M. stolzmanni $\left(\mathrm{B}^{\prime}=2.79\right)$. This is consistent with Bergallo and Rocha's (1994) observation that actively foraging species can be more selective in food choice, resulting in lower food diversity. In contrast, sit-and-wait predators, such as $P$. peruvianus, spend more time motionless and consume a wide variety of prey types, depending on what passes by (Vitt and Caldwell 2013).

Microlophus stolzmanni is considered as Least Concern by the IUCN Red List of Threatened Species (Venegas et al. 2016) and was found in high densities in most surveyed localities of the inter-Andean dry-forest valleys in northern Peru. Nevertheless, as Beuttner and Koch (2019) and Koch et al. (2013) pointed out, most of these surveyed localities face multiple, complex threats that may lead to habitat loss or fragmentation. To our knowledge, M. stolzmanni does not occur in any protected area, and there is limited information in the literature about natural history, distribution and population sizes of the species. Thus, we cannot assess the effect of potential habitat threats that might lead to a populational decline of the species. 


\section{Acknowledgments}

We thank the Deutscher Akademischer Austauschdienst (DAAD), the Alexander Koenig Stiftung (AKS) and the Alexander Koenig Gesellschaft (AKG) for financial support. The Ministerio de Agricultura of Peru kindly provided collecting (071-2008-INRENA-IFFSDCB, 0020-2009-AG-DGFFS-DGEFFS, 0424-2010-AG-DGFFS-DGEFFS) and export permits (0017799-AG-INRENA， 001829-AGDGFFS, 003983-AG-DGFFS). For assistance during fieldwork we are indebted to Alfredo Beraún, Sibylle Duran Zopazo, Marco Enciso, Antonio Garcia Bravo, Erick Hoyos Granda, Jorge Novoa Cova, Napoleon Monsalve, and Manuel Palacios Panta.

\section{References}

Anderson, R. A. and W. H. Karasov. 1988. Energetics of the lizard Cnemidophorus tigris and life history consequences of food-acquisition mode. Ecological Monographs 58: 79-110.

Bährmann, R. 2011. Bestimmung Wirbelloser Tiere. $6^{\text {th }}$ Edition. Heidelberg. Spektrum Akademischer Verlag. $390 \mathrm{pp}$.

Benavides, E., R. Baum, D. McClellan, and J. W. Sites. 2007. Molecular phylogenetics of the lizard genus Microlophus (Squamata, Tropiduridae): aligning and retrieving indel signal from nuclear introns. Systematic Biology 56: 776-797.

Benavides, E., R. Baum, H. M. Snell, H. L. Snell, and J. W. Sites. 2009. Island biogeography of Galápagos Lava Lizards (Tropiduridae: Microlophus): species diversity and colonization of the Archipelago. Evolution 63: $1606-1626$.

Bergallo, H. G. and C. F. D. Rocha. 1994. Spatial and trophic niche differentiation in two sympatric lizards (Tropidurus torquatus and Cnemidophorus ocellifer) with different foraging tactics. Australian Journal of Ecology 19: 7275.

Beuttner, A. and C. Koch. 2019. Analysis of diet composition and morphological characters of the little known Peruvian bush anole Polychrus peruvianus (Noble, 1924) in a northern Peruvian dry forest. Amphibian and Reptile Conservation 13: 111-121.
Colli, G. R. and D. S. Zamboni. 1999. Ecology of the wormlizard Amphisbaena alba in the Cerrado of central Brazil. Copeia 1999: 733-742.

Cooper, W. E. and L. J. Vitt. 2002. Distribution, extent, and evolution of plant consumption by lizards. Journal of Zoology 257: 487-517.

Dessem, D. 1985. Ontogenetic changes in the dentition and diet of Tupinambis (Lacerta: Teiidae). Copeia 1985: 245-247.

Dixon, J. R. and J. W. Wright. 1975. A review of the lizards of the iguanid genus Tropidurus in Peru. Contributions in Science, Natural History Museum of Los Angeles County 271: 1-39.

Estes, R. and E. E. Williams. 1984. Ontogenetic variation in the molariform teeth of lizards. Journal of Vertebrate Paleontology 4: 96-107.

Frost, D. R. 1992. Phylogenetic analysis and taxonomy of the Tropidurus group of lizards (Iguania: Tropiduridae). American Museum Novitates 3033: 1-68.

Frost, D. R., M. T. Rodrigues, T. Grant, and T. A. Titus. 2001. Phylogenetics of the lizard genus Tropidurus (Squamata: Tropiduridae: Tropidurinae): direct optimization, descriptive efficiency, and sensitivity analysis of congruence between molecular data and morphology. Molecular Phylogenetics and Evolution 21: $352-371$.

Griffiths, A. D. and K. A. Christian. 1996. Diet and habitat use of frillneck lizards in a seasonal tropical environment. Oecologia 106: 39-48.

Harvey, M. B. and R. L. Gutberlet Jr. 2000. A phylogenetic analysis of tropidurine lizards (Squamata: Tropiduridae), including new characters of squamation and epidermal microstructure. Zoological Journal of the Linnean Society 128: 189-233.

Herrel, A. 2007. Herbivory and foraging mode in lizards. Pp. 209-236 in S. M. Reilly, L. D. McBrayer, and D. B. Miles (eds.), Lizard Ecology: The Evolutionary Consequences of Foraging Mode. Cambridge. Cambridge University Press.

Herrel, A., E. De Grauw, and J. A. Lemos-Espinal. 2001a. Head shape and bite performance in xenosaurid lizards. Journal of Experimental Zoology 290: 101-107.

Herrel, A., R. Van Damme, B. Vanhooydonck, and F. De Vree. 2001b. The implication of bite performance in two species of lacertid lizards. Canadian Journal of Zoology 79: 662-670.

Huyghe, K., A. Herrel, D. Adriaens, Z. Tadic, and R. van Damme. 2009. It is all in the head: morphological basis 
in bite force among colour morphs of the Dalmatian wall lizard. Biological Journal of the Linnean Society 96: $13-22$.

Huey, R. B. and E. R. Pianka. 1981. Ecological consequences of foraging mode. Ecology 62: 991-999.

Ibáñez, S., M. A. Vidal, J. C. Ortiz, and F. Torres-Pérez. 2015. Geometric morphometric analysis of the head of Microlophus atacamensis (Tropiduridae) in a latitudinal gradient. Zoological Studies 54: 24.

Johnson, R. N. and H. B. Lillywhite. 1979. Digestive efficiency of the omnivorous lizard Klauberina riversiana. Copeia 1979: 431-437.

Koch, C., P. J. Venegas, D. Rödder, and W. Böhme. 2013. Two new endemic species of Ameiva (Squamata: Teiidae) from the dry forest of northwestern Peru and additional information on Ameiva concolor Ruthven, 1924. Zootaxa 3745: 263-295.

Koch, C., P. J. Venegas, R. Santa-Cruz, and W. Böhme. 2018. Annotated checklist and key to the species of amphibians and reptiles inhabiting the northern Peruvian dry forest along the Andean valley of the Marañón River and its tributaries. Zootaxa 4385: 1-101.

Magnusson, W. E., L. J. Paiva, R. M. Rocha, C. R. Franke, L. A. Kasper, and A. P. Lima. 1985. The correlates of foraging mode in a community of Brazilian lizards. Herpetologica 41: 324-335.

Mayhew, W. W. 1963. Some food preferences of captive Sauromalus obesus. Herpetologica 19: 10-16.

McBrayer, L. D. and C. E. Corbin. 2007. Patterns of head shape variation in lizards: morphological correlates of foraging mode. Pp. 271-301 in S. M. Reilly, L. D. McBrayer, and D. B. Miles (eds.), Lizard Ecology: The Evolutionary Consequences of Foraging Mode. Cambridge. Cambridge University Press.

Meyers, J. J., A. Herrel, and J. Birch. 2002. Scaling of morphology, bite force and feeding kinematics in an iguanian and a scleroglossan lizard. Pp. 47-62 in P. Aerts, K. D'Août, A. Herrel, and R. van Damme (eds.), Topics in Functional and Ecological Vertebrate Morphology. Maastricht. Shaker Publishing.

Miles, D. B., J. B. Losos, and D. J. Irschick. 2007. Morphology, performance and foraging mode. Pp. 49-93 in S. M. Reilly, L. D. McBrayer, and D. B. Miles (eds.), Lizard Ecology: The Evolutionary Consequences of Foraging Mode. Cambridge. Cambridge University Press.

Nagy, K. A., R. B. Huey, and A. F. Bennett. 1984. Field energetics and foraging mode of Kalahari lacertid lizards. Ecology 65: 588-596.

Ortiz, J.C. and I. Serey. 1979. Análisis factorial de correspondencias de las especies del género Tropidurus en
Chile. Archivos de Biologia y Medicina Experimentales 12: 203-208.

Paulissen, M. A. 1988. Ontogenetic and seasonal shifts in microhabitat use by the lizard Cnernidophorus sexlineatus. Copeia 1988: 1021-1029.

Pérez, Z. J., E. Fuentes, and J. Jordán. 2015. Dieta de la lagartija de los gramadales Microlophus thoracicus icae en el valle del río Ica, Perú. Revista Peruana de Biología 22: $233-238$.

Pianka, E. R. 1970. Comparative autecology of the lizard Cnemidophorus tigris in different parts of its geographic range. Ecology 51: 703-720.

Pianka, E. R. 1974. Niche overlap and diffuse competition. Proceedings of the National Academy of Sciences of the United States of America 71: 2141-2145.

Pianka, E. R. and W. S. Parker. 1975. Ecology of horned lizards: a review with special reference to Phrynosoma platyrhinos. Copeia 1975: 141-162.

Pinkas, L. 1971. Food habits study. Fish Bulletin 152: 5-10.

Pinkas, L., M. S. Oliphant, and I. L. K. Iverson 1971. Food habits of albacore, bluefin tuna, and bonito in Californian waters. Fish Bulletin 152: 11-105.

Quispitúpac, E. and J. Perez. 2009. Dieta de la lagartija de las playas Microlophus peruvianus en la playa Santo Domingo. Reserva Nacional de Paracas, Ica. Revista Peruana de Biologia 15: 129-130.

Simpson, E. H. 1949. Measurement of diversity. Nature 163: 688 .

Toft, C. A. 1985. Resource partitioning in amphibians and reptiles. Copeia 1985: 1-21.

Toyama, K. S. 2016. Evidence of adaptive evolution in the cranial morphology of tropidurid lizards from coastal Peru. Herpetology Notes 9: 47-53.

Troyer, K. 1982. Transfer of fermentative microbes between generations in a herbivorous lizard. Science 216: 540542.

van Leeuwen, J. P., A. Catenazzi, and M. Holmgren. 2011. Spatial, ontogenetic, and sexual effects on the diet of a teiid lizard in arid South America. Journal of Herpetology 45: 472-477.

Venegas, P., J. Perez, and A. Quiroz Rodriguez. 2016. Microlophus stolzmanni. The IUCN Red List of Threatened Species 2016. e.T48444267A48444274. Electronic Database accessible at http://dx.doi. or g / 10.2305 / I U C N. U K . 2016 - 1. R L T S . T48444267A48444274.en. Captured on 27 July 2018. 
Verwaijen, D., R. van Damme, and A. Herrel. 2002. Relationships between head size, bite force, prey handling efficiency and diet in two sympatric lacertid lizards. Functional Ecology 16: 842-850.

Vidal, M., J. C. Ortiz, and A. Labra. 2002. Sexual and age differences in ecological variables of lizard Microlophus atacamensis (Tropiduridae) from northern Chile. Revista Chilena de Historia Natural 75: 283-292.
Vitt, L. J. and J. P. Caldwell. 2013. Herpetology: An Introductory Biology of Amphibians and Reptiles. $4^{\text {th }}$ Edition. Amsterdam. Elsevier. 776 pp.

Watkins, G. G. 1996. Proximate causes of sexual size dimorphism in the iguanian lizard Microlophus occipitalis. Ecology 77: 1473-1482.

Editor: Jaime Bertoluci

Appendix I. Specimens examined.

Microlophus stolzmanni: PERU. Amazonas: Bagua: Bagua Grande: ZFMK 88723 (05²47'33.3" S, 78²3'04.9" W, 568 m a.s.1.); Bagua Chica: ZFMK 88724, 88725 (0538'06.9" S, 78³2'27.7" W, 500 m a.s.1.); Utcubamba: Cumba: ZFMK 90855, 90856 (0556'14.6" S, 78³9'50.4" W, 465 m a.s.1.); Chachapoyas: Balsas: ZFMK 90847 (0650'20.7" S, 7801'23.3" W, 859 m a.s.1.); ZFMK 90848 (06 $50^{\prime} 54.3^{\prime \prime}$ S, 7800'01.5" W, 1065 m a.s.1.); Quebrada Honda / Llusca: ZFMK 85021-85023

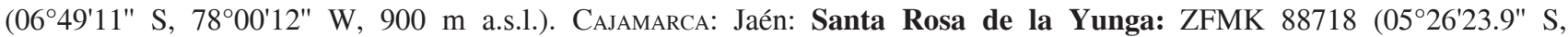
78³3'16.7" W, 1273 m a.s.1.); ZFMK 88719, 88720 (05²6'17.3" S, 78³3'12.7" W, 1280 m a.s.1.); Bellavista: ZFMK 88715 $\left(05^{\circ} 38^{\prime} 02.9^{\prime \prime} \mathrm{S}, 78^{\circ} 38^{\prime} 08.1^{\prime \prime} \mathrm{W}, 447 \mathrm{~m}\right.$ a.s.1.); ZFMK $90845\left(05^{\circ} 37^{\prime} 27.6^{\prime \prime} \mathrm{S}, 78^{\circ} 38^{\prime} 49.5^{\prime \prime} \mathrm{W}, 434 \mathrm{~m}\right.$ a.s.1.); ZFMK 90846 (05³0'29.0" S, 78³0'23.6" W, 444 m a.s.1.); Gotas de Agua: ZFMK 88716, 88717 (05²4'08.9" S, 78²4'22.5" W, 660 m a.s.1.); Pucará: ZFMK 88721, 90839-90841 (0602'23.0" S, 7907'59.4" W, $901 \mathrm{~m}$ a.s.1.); ZFMK 88722 (0601'59.2" S, 7907'27.7" W, 966 m a.s.1.); ZFMK 90842, 90843 (0602'37.1" S, 7908'15.5" W, 965 m a.s.1.); ZFMK 90844 (0603'36.1" S, 7903'16.4" W, 949 m a.s.1.); Cutervo: Across from Cumba: ZFMK 90857 (0554'24.1" S, 78³9'50.4" W, 465 m a.s.1.); Celendín: Chacanto: ZFMK 90850 (0650'59.0" S, 7802'14.6" W, 1087 m a.s.1.); ZFMK 90849 (0651'08.9" S, 7801'58.2" W, 992 m a.s.1.); ZFMK 90851 (0651'14.1" S, 7801'40.1" W, 969 m a.s.1.). LA LiBERTAD: Bambamarca: Calemar: ZFMK 91784-91786 (07³2' S, 77²43' W, 1108-1340 m a.s.1.); Bolívar: San Vicente / Pusac: ZFMK 90852-90854 (06 $59^{\circ}$ ' S, $77^{\circ} 55^{\prime}$

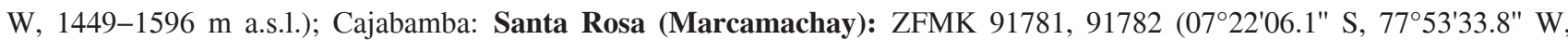
1185 m a.s.1.); ZFMK 91783 (07²2'03.9" S, 7753'54.5" W, 1235 m a.s.1.); Pataz: Chagual: ZFMK 91771, 91772 (0750' S,

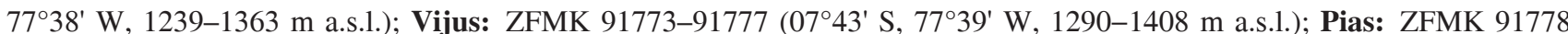

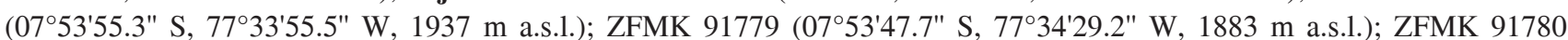
(07'53'41.0" S, 77³3'58.3" W, 1952 m a.s.1.). 
Analysis of diet composition and morphological characters of Microlophus stolzmanni

Appendix II. Mean values of prey-item sizes to estimate the length and width of incomplete prey items for each prey taxon. Taxa represented by only complete items are not listed.

\begin{tabular}{|c|c|c|c|}
\hline Prey taxon & Size & Body length (mm) & Body width (mm) \\
\hline \multirow[t]{4}{*}{ Araneae } & exceedingly large & 5.0 & 2.6 \\
\hline & medium & 3.6 & 1.9 \\
\hline & small & 1.9 & 1.2 \\
\hline & minute & 0.9 & 0.5 \\
\hline \multirow[t]{4}{*}{ Coleoptera } & exceedingly large & 16.4 & 10.9 \\
\hline & large & 12.8 & 3.7 \\
\hline & medium & 4.7 & 2.9 \\
\hline & small & 2.3 & 0.9 \\
\hline \multirow[t]{5}{*}{ Formicidae } & exceedingly large & 8.9 & 2.7 \\
\hline & large & 6.8 & 2.3 \\
\hline & medium & 4.0 & 0.9 \\
\hline & small & 2.3 & 0.6 \\
\hline & minute & 1.6 & 0.4 \\
\hline \multirow[t]{3}{*}{ Heteroptera } & large & 11.6 & 6.3 \\
\hline & medium & 8.9 & 5.1 \\
\hline & small & 4.8 & 2.3 \\
\hline \multirow[t]{2}{*}{ Hymenoptera } & medium & 9.5 & 3.9 \\
\hline & small & 8.1 & 2.7 \\
\hline \multirow[t]{2}{*}{ Isoptera } & medium & 6.4 & 2.0 \\
\hline & small & 3.9 & 1.1 \\
\hline \multirow[t]{4}{*}{ Lepidoptera Larve } & large & 29.9 & 4.9 \\
\hline & medium & 14.2 & 3.2 \\
\hline & small & 10.0 & 1.3 \\
\hline & minute & 3.7 & 0.9 \\
\hline \multirow[t]{2}{*}{ Orthoptera } & large & 17.4 & 4.5 \\
\hline & medium & 13.1 & 3.2 \\
\hline
\end{tabular}


Appendix III. Measurements (range/ \pm SD) of Microlophus stolzmanni. Snout-vent length (mm), body width (mm), body weight $(\mathrm{g})$, head length $(\mathrm{mm})$, head width $(\mathrm{mm})$, head height $(\mathrm{mm})$, fat body weight $(\mathrm{g})$, percental fat body weight $(\%)$,stomach weight ( $g$ ), and percental stomach weight (\%) of females, males, juveniles and all animals together (total). Shown is the range, the mean value $(\bar{x})$ and the standard deviation $(S D)$.

\begin{tabular}{|c|c|c|c|c|}
\hline & Females & Males & Juveniles & Total \\
\hline$N_{\text {specimens }} / N_{\text {fat bodies }}$ & $14 / 11$ & $24 / 22$ & $11 / 5$ & $49 / 38$ \\
\hline \multirow[t]{2}{*}{ Snout-vent length (mm) } & $52-100$ & $66-138$ & $27-56$ & $27-138$ \\
\hline & $65.1 \pm 10.3$ & $97.2 \pm 18.2$ & $40.6 \pm 8.8$ & $75.3 \pm 27.3$ \\
\hline \multirow[t]{2}{*}{ Body weight (g) } & $14-33$ & $15-40$ & $7-12$ & $7-40$ \\
\hline & $18.6 \pm 4.5$ & $25.5 \pm 5.7$ & $9.9 \pm 2.1$ & $20.0 \pm 7.8$ \\
\hline \multirow[t]{2}{*}{ Head length (mm) } & $5-36$ & 9-99 & $1-5$ & $1-99$ \\
\hline & $10.6 \pm 7.4$ & $38.3 \pm 22.8$ & $2.8 \pm 1.4$ & $22.4 \pm 22.8$ \\
\hline \multirow[t]{2}{*}{ Head width (mm) } & $15-26$ & $19-35$ & $9-15$ & $9-35$ \\
\hline & $17.0 \pm 2.7$ & $26.0 \pm 3.7$ & $11.7 \pm 2.3$ & $20.2 \pm 6.8$ \\
\hline \multirow[t]{2}{*}{ Head height (mm) } & $9-20$ & $12-23$ & $6-11$ & $6-23$ \\
\hline & $11.7 \pm 2.4$ & $17.4 \pm 2.8$ & $8.1 \pm 1.3$ & $13.7 \pm 4.6$ \\
\hline \multirow[t]{2}{*}{ Fat body weight (g) } & $0.01-0.4$ & $0.01-1.1$ & $0.01-0.01$ & $0.01-1.1$ \\
\hline & $0.11 \pm 0.13$ & $0.13 \pm 0.24$ & $0.01 \pm 0.00$ & $0.11 \pm 0.20$ \\
\hline \multirow[t]{2}{*}{ Fat body weight (\%) } & $0.1-4.1$ & $0.03-1.1$ & $0.2-0.9$ & $0.03-4.1$ \\
\hline & $0.91 \pm 1.10$ & $0.22 \pm 0.27$ & $0.49 \pm 0.31$ & $0.46 \pm 0.70$ \\
\hline \multirow[t]{2}{*}{ Stomach weight (g) } & $0.1-0.8$ & $0.2-2.8$ & $0.01-0.3$ & $0.01-2.8$ \\
\hline & $0.34 \pm 0.21$ & $1.07 \pm 0.66$ & $0.12 \pm 0.08$ & $0.65 \pm 0.63$ \\
\hline \multirow[t]{2}{*}{ Stomach weight (\%) } & $1.0-8.3$ & $1.1-8.6$ & $0.9-7.6$ & $0.9-8.6$ \\
\hline & $3.64 \pm 2.10$ & $3.04 \pm 1.62$ & $4.22 \pm 2.30$ & $3.48 \pm 1.99$ \\
\hline
\end{tabular}

